MDPI is a member of

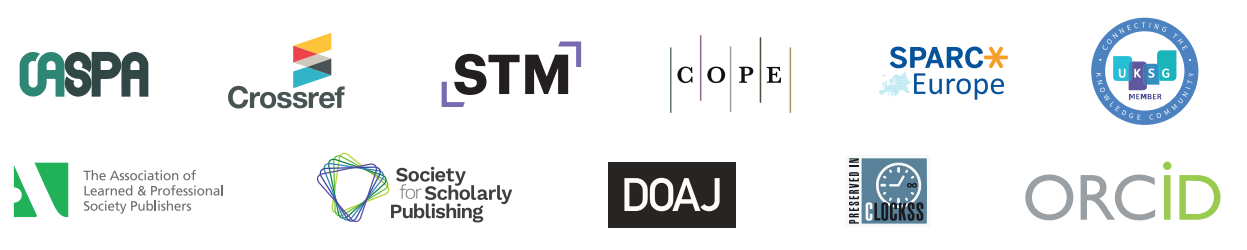

Affiliated Societies

Ifilmaterials

an Open Access Journal by MDPI

socie 6 mat sociedad española da

Follow

f facebook.com/MDPIOpenAccessPublishing

3. twitter.com/MDPIOpenAccess

in linkedin.com/company/mdpi

(0) instagram.com/mdpiopenaccess

6" weibo.com/mdpicn

Wechat:MDPI-China

\title{
Subscribe
}

blog.mdpi.com

Visit mdpi.com for a full list of offices and contact information.

MDPI is a company registered in Basel, Switzerland, No. CH-270.3.014.334-3,

whose registered office is at St. Alban-Anlage 66, CH-4052 Basel, Switzerland.

\section{Academic Open Access Publishing}

\section{IMPACT CITESCORE}

3.748

4.7

Affiliated Societies

Manufacturing Engineering Society (MES)

- Portuguese Materials Society (SPM)

- Spanish Materials Society (SOCIEMAT) 
an Open Access Journal by MDPI

Editor-in-Chief

Prof. Dr. Maryam Tabrizian

Associate Editors-in-Chief

Dr. Christof Schneider

Prof. Dr. Filippo Berto

Prof. Dr. Guillermo Requena

\section{Author Benefits}

Open Access Unlimited and free access for readers

C No Copyright Constraints Retain copyright of your work and free use of your article

\section{\&. Thorough Peer-Review}

\section{IF) 2021 Impact Factor: 3.748 (Journal Citation Reports - Clarivate, 2022)}

I] No Space Constraints, No Extra Space or Color Charges No restriction on the length of the papers, number of figures or colors

Ad Coverage by Leading Indexing Services Scopus, SCIE (Web of Science),

PubMed, PMC, Ei Compendex, CaPlus / SciFinder, Inspec, Astrophysics Data System, and other databases

(-) Rapid Publication First decision is provided to authors approximately 13.9 days after submission; acceptance to publication is undertaken in 3.5 days (median values for papers published in this journal in the second half of 2022)

\section{Aims and Scope}

Materials provides a forum for publishing papers that advance in-depth understandings of the relationships between the structures, properties, applications or functions of all classes of materials. We aim to encourage various scientific communities to publish their original experimental and theoretical research, as well as thei reviews.

\section{The scope of Materials includes:}

All classes of materials, including ceramics, glasses, polymers (plastics), semiconductors, magnetic materials, medical implant materials and biological materials, silica and carbon materials, and metals and metallic alloys

Functional materials

Characterization techniques, such as electron microscopy, x-ray diffraction, among others

Fundamental research: condensed matter and materials physics and the mechanics of materials

Various topics related to materials science or materials engineering, nanomaterials, and nanotechnology
Section Editors-in-Chief Dr. Fabrizio Roccaforte Dr. Francesco Baino Dr. Ingo Dierking Prof. Dr. Alessandro Pegoretti Prof. Dr. Carlos Lodeiro Prof. Dr. Eddie Koenders Prof. Dr. Federico Bella Prof. Dr. Heesun Yang Prof. Dr. Javier Gil

Prof. Dr. Katsuhiko Ariga Prof. Dr. Konstantinos Salonitis Prof. Dr. Miguel A. Camblor Prof. Dr. Nikolas J. Podraza Prof. Dr. Panagiotis G. Asteris Prof. Dr. Pascal Van Der Voort Prof. Dr. Raman Singh Prof. Dr. Sanjay Mathur Prof. Dr. Sanjay Mathu

Prof. Dr. Stefano Belluce Prof. Dr. Steven L. Suib Prof. Dr. Steven L. Suib
Prof. Dr. Valery V. Tuchin Prof. Dr. Vlassios Likodimos Prof. Dr. Xiaoyan Li Prof. Dr. Xuming Xie Prof. Dr. Yong-Cheng Lin

Editorial Office Materials Editorial Office materials@mdpi.com MDPI, St. Alban-Anlage 66 4052 Basel, Switzerland Tel: +41 616837734 www.mdpi.com mdpi.com/journal/materials 